\title{
DIABETIC NEUROPATHY: AN \\ EVALUATION USING THE NTSS-6 \\ QUESTIONAIRE AND \\ BIOTHESIOMETRY IN TYPE 2 DM PATIENTS IN SOUTHWEST NIGERIA.
}


Å Lawal Bello AT, Owolabi FA Yusuff OT Amjo O, Raiyemo AO, Kolawole BT, Ikem RT.

Å Division of EDM, Dept of Medicine, Obafemi Awolowo University Teaching Hospital Ile Ife, Nigeria. 


\section{Å Background \& objectives: Vibration} perception threshold (VPT) is the gold standard for diagnosis of diabetic peripheral neuropathy. The relationship between symptom severity and VPT remains to be determined. This study was carried out to evaluate the objectivity of symptoms using the NTSS- 6 and Bio-Thesiometry. 
$\AA$ Methods: The study was conducted in the Diabetes Clinic of Obafemi Awolowo University Teaching Hospital Ile Ife, a tertiary care hospital in South West, Nigeria, A crosssectional case control study involving 110 diabetes patients with symptoms suggestive of peripheral neuropathy as well as 40 apparently healthy control. Detailed clinical history were taken and subject were examined 
A Neuropathy total symptoms score-6 questionnaires was administered. The questionnaire, evaluates for the frequency and intensity of 6 core symptoms of peripheral neuropathy, Possible scores for the NTSS-6 range from 0-21.96. Clinical significant symptoms was defined as an NTSS- 6 total score greater than 6 .

$\AA$ vibration perception threshold (VPT) was tested with a biothesiometer model Biothezi-

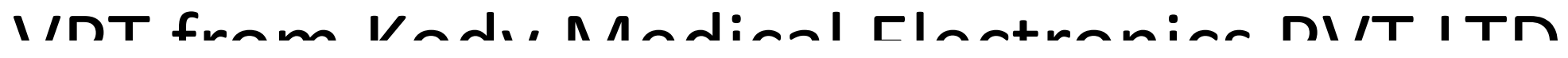


Å Results: The prevalence of peripheral neuropathy using the NTSS-6 scoring system was $50 \%$ while VPT using biothesiometer was $45.5 \%$.

A Significant correlations were observed between the NTSS- 6 score and the VPT score. ( $p$-value $=0.002$ ( $r$ ) 0.588).

$\AA$ The NTSS- 6 scoring had a sensitivity of $66 \%$ and a specificity of 66.3\%. Age and BMI were statistically significantly associated with clinically significant neuropathy. Numbness 


\section{$\approx 1$ II Your complimentary - Comperiod has ended. ¿ Complete \\ ce of Clinically significant neuropathy}

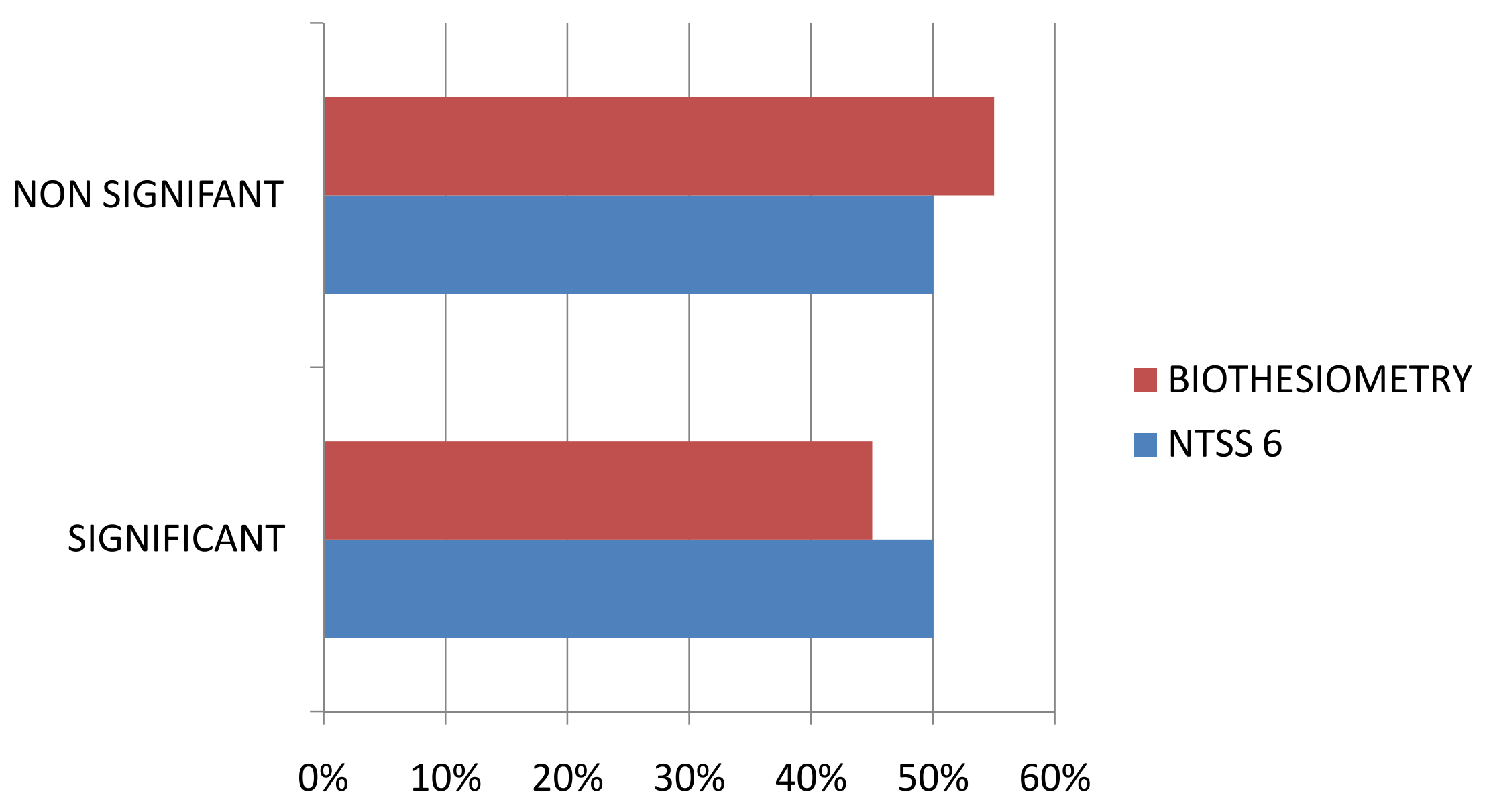




\begin{tabular}{|lr|}
\hline Complete & $\begin{array}{r}\text { Your complimentary } \\
\text { use period has ended. } \\
\text { Thank you for using } \\
\text { PDF Complete. }\end{array}$ \\
\hline $\begin{array}{l}\text { Click Here to upgrade to } \\
\text { Unlimited Pages and Expanded }\end{array}$ \\
\hline
\end{tabular}

Mean score on NTSS 6

3.00

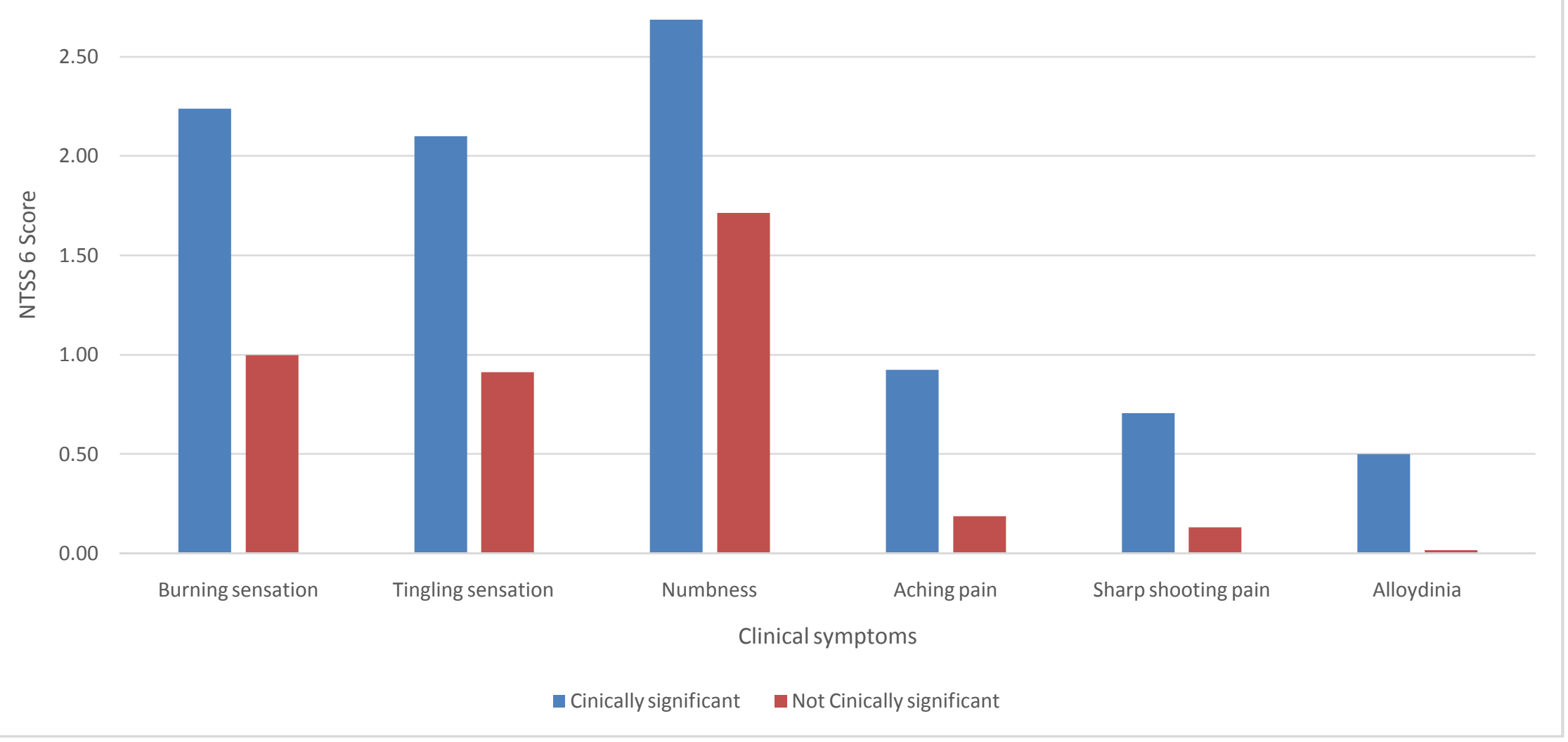


A Interpretation \& conclusions: The findings show that Symptoms suggestive of peripheral neuropathy (PN) in diabetes mellitus (DM) do not always indicate presence of underlying $P N$. Neuropathy questionnaires are useful for assessing peripheral diabetic neuropathy and correlate well with biothesiometry finding.

A Key words: Diabetic mellitus, peripheral neuropathy, Neuropathy total symptoms score6, Bio-thesiometry. 